\title{
O acompanhamento terapêutico e sua caracterização em Betim e Belo Horizonte
}

\author{
Therapeutic accompaniment and its characteristics in Betim and Belo Horizonte \\ El seguimiento terapéutico y su característica en Betim y Belo Horizonte
}

Anamaria Batista Nogueira*

\begin{abstract}
Resumo
Após uma revisão bibliográfica sobre a história do acompanhamento terapêutico (AT), juntamente com uma pesquisa feita entre trabalhadores da saúde mental em Belo Horizonte pela UFMG (Universidade Federal de Minas Gerais), propõe-se uma caracterização do AT, desde sua origem até as perspectivas atuais. Como campo para viabilizar tal pesquisa, as cidades de Belo Horizonte e Betim nos serviram como referências, uma vez que são, respectivamente, pioneiras na execução desse dispositivo clínico em Minas Gerais. Pode-se perceber que há tanto avanços na prática clínica do AT quanto impasses gerados por ela no campo da saúde mental. A função, orientação teórica, finalidade e tipos de indicações poderão nos servir como pontos de apoio que delineiam a clínica do AT no contexto atual.
\end{abstract}

Palavras-chave: acompanhamento terapêutico; psicose; rede pública.

\begin{abstract}
After a bibliographic review of the history of Therapeutic Accompaniment (TA) and a research carried out with professionals of mental health by the Universidade Federal de Minas Gerais - UFMG (Federal University of Minas Gerais) in Belo Horizonte, a description of the TA purposes is provided from its origins to the present day. The research took place in Belo Horizonte and Betim, cities known as references in the field and pioneer in promoting and applying this clinical technique in Minas Gerais State. One notices that there is as much progress as there are obstacles in TA clinical practice in mental health. Its function, theoretic tendencies, purposes and indications can work as reference to describe TA clinical practice in the present context.
\end{abstract}

Keywords: Therapeutic Accompaniment; Psychosis; Net Public Service.

Texto recebido em outubro de 2008 e aprovado para publicação em setembro de 2009.

Mestra em Psicologia pela Universidade Federal de Minas Gerais, pós-graduada em Psicologia Clínica pela PUC Minas (Betim) - UFMG, e-mail: anabano@ig.com.br. 


\section{Resumen}

Después de una revisión bibliográfica sobre la historia del Seguimiento Terapéutico (AT), conjuntamente con una investigación hecha por la UFMG (Universidad Federal de Minas Gerais) entre los trabajadores de la salud mental de Belo Horizonte, se propone una caracterización de AT, desde su origen hasta sus perspectivas actuales. Como campo para conducir la investigación, las ciudades de Belo Horizonte y Betim, nos sirvieron como referencia, dado que son iniciadoras en la ejecución de ese dispositivo clínico en Minas Gerais. Se puede ver que hay tantos avances en la práctica clínica de AT, como obstáculos generados por esta, en el campo de la salud mental. La función, orientación teórica, finalidades y tipos de indicaciones podrán servirnos como puntos de apoyo que delinean la clínica de AT en el contexto actual.

Palabras clave: Seguimiento Terapéutico; Psicosis; Red Pública de Servicio.

\section{Introdução}

1 pesquisa Acompanhamento terapêutico na psicose: um percurso histórico $\triangle$ na Grande BH, concluída em 2006, foi proposta como um dos pontos metodológicos para parte do desenvolvimento da dissertação $O$ acompanhamento terapêutico na psicose: possibilidades de uma orientação analitica, defendida na Fafich/UFMG, em 2007, por Anamaria Batista Nogueira, sob a orientação de Dr. Oswaldo França Neto ${ }^{1}$.

A proposta dessa pesquisa foi investigar o percurso histórico do AT aplicado à psicose na Grande $\mathrm{BH}$, desde o surgimento até a posição atual. Para tanto, o projeto consistiu primeiramente em uma pesquisa de campo ${ }^{2}$ sobre o tema proposto e, posteriormente, em uma articulação histórica entre essa investigação e as referências bibliográficas sobre ao tema, apresentadas em setembro de 2006, em São Paulo, no I Congresso Internacional, II Congresso Ibero-americano e I Congresso Brasileiro de Acompanhamento Terapêutico "Singularidade, Multiplicidade e Ações de Cidadania”.

\footnotetext{
Doutor em Psicanálise pela Universidade Federal do Rio de Janeiro (2001), mestre em Teoria Psicanalítica pela Universidade Federal do Rio de Janeiro (1996) e graduado em Medicina pela Universidade Federal de Minas Gerais (1983). Atualmente é professor adjunto do Programa de Pós-graduação do Departamento de Psicologia da Universidade Federal de Minas Gerais e membro do GT da ANPEPP "Dispositivos clínicos em saúde mental".

2 Entrevistas com profissionais do campo de Saúde Mental, que contribuíram com a introdução do AT em Minas Gerais. Elas foram feitas por Anamaria Batista Nogueira, na época, mestranda em Psicologia pela UFMG, e redigidas por Fabiane Amorim de Paula e Diego Alexandre Gomes Sousa, estudantes do $5^{\circ}$ período de Psicologia pela UFMG. Orientador da pesquisa: Dr. Oswaldo França Neto.
} 
Um problema levantado por meio dessa pesquisa diz respeito à multiplicidade de influências que delineiam esse recurso terapêutico, que acabou tornandose, então, uma prática pouco delimitada e mesmo vaga no que se refere à sua orientação clínica. A expressão "acompanhamento terapêutico" é usada nas clínicas e instituições psiquiátricas no tratamento com psicóticos, mas também em escolas especiais com alunos com deficiência mental, no tratamento de autistas, idosos e até mesmo com crianças com dificuldades de aprendizagem, demonstrando-nos uma dificuldade para definir seu campo e seu modo de atuação. A nomenclatura "acompanhamento terapêutico", portanto, não se limita ao tratamento da psicose. A especificidade de uma prática começou a se perder.

A pesquisa sobre a história do AT na Grande BH, pela UFMG, seria um meio de situar Minas Gerais no contexto de tal modalidade clínica que se destaca, atualmente, em escala internacional.

\section{Origem}

Alguns estudiosos, como Barretto (2006) ${ }^{3}$, Berger et al. (1991), Cauchick (2001), Pitiá e Santos (2005), afirmam que a origem da AT deve-se à forte influência de movimentos na história da psiquiatria que mudaram a forma de tratamento dos portadores de sofrimento mental, culminando nas raízes do que hoje se tornou uma prática clínica.

Movimentos como antipsiquiatria, liderado por Laing e Cooper na Inglaterra; a psiquiatria democrática, representada por Basaglia na Itália; e a psicoterapia institucional, caracterizada por Oury e Guattari na França, tornaram-se, no século XX, formas de se contestar o tratamento psiquiátrico proposto até então, o que abriu espaço a novas construções de tratamento como as comunidades terapêuticas, o hospital-dia e, posteriormente, o AT.

O modelo de assistência à saúde mental no Brasil, a partir de 1960, passou a sofrer influências das comunidades terapêuticas americanas na sua forma de estruturação. Em Porto Alegre, na comunidade terapêutica Clínica Pinel, tentou-se implantar a filosofia de um Hospital Dinâmico, surgindo a figura do atendente psiquiátrico, cuja função seria acompanhar os pacientes internos em sua rotina, passeios, visitas a outros médicos, entre outras situaçóes (Barretto, 2006). O estabelecimento dessa mais nova função não exigia formação acadêmica para lidar com os pacientes em tratamento. Em 1969, no Rio de

Palestra proferida no Curso de formação Acompanhamento Terapêutico: origens e perspectivas, por Kleber Duarte Barretto, Edições Sobornost, São Paulo e gravado em CD-R, 2006. 
Janeiro, um grupo de psicanalistas fundou a comunidade terapêutica Clínica Villa Pinheiros, com o apoio e influência do modelo estrutural da Clínica Pinel, que indicou alguns atendentes psiquiátricos para ajudá-los na sua estruturação. Porém os atendentes psiquiátricos passaram a ser chamados de auxiliares psiquiátricos, e sua função ganhou interesse de estudantes de Psicologia e de Medicina. Consequentemente, ampliou-se o número de pessoas que exerciam tal função, com ou sem formação acadêmica, e essas passaram a participar de reuniôes em que se discutiam casos atendidos sob referencial da teoria psicanalítica. No sentido de evitar internações, alguns psiquiatras reconheciam o valor do trabalho dos auxiliares psiquiátricos e começarem a indicá-los para atendimento de psicóticos mesmo fora das instituiçôes (Barretto, 2006).

$\mathrm{Na}$ Clínica Villa Pinheiros, além do trabalho feito dentro da instituição, como ajudar os pacientes a se organizar na rotina, no que se refere à higiene pessoal, “[...] tornou-se também frequente o acompanhamento fora da instituição [...]" (Reis Neto, 1995, p. 2), como visitas à família, passeios, cumprimento de compromissos pessoais, consultas médicas.

Em 1976, com a crise no Brasil acarretada pela ditadura, fechou-se a Clínica Villa Pinheiros, porém o trabalho dos auxiliares psiquiátricos continuou a exercer influência no tratamento dos portadores de sofrimento mental, apesar do retrocesso na sua função, a partir do retorno à antiga psiquiatrização. Os auxiliares psiquiátricos, sob influência da crise política, que exercia uma forma de controle sobre os cidadãos, passaram a vigiar e conter os pacientes. Por outro lado, a experiência clínica sobrepôs-se às novas condições político-sociais, e os auxiliares psiquiátricos continuaram a ganhar corpo no tratamento da psicose (Barretto, 2006). As indicações ao tratamento com os auxiliares não foram mais motivadas apenas pela demanda de evitar internações. "Com o tempo, pacientes fora de crise também são indicados aos auxiliares psiquiátricos" (Reis Neto, 1995, p. 3). Outra nova característica desse dispositivo clínico é a inserção do auxiliar em uma equipe terapêutica, composta por um psiquiatra e, frequentemente, por mais um profissional, seja por um psicanalista, um terapeuta individual ou de família.

Até então, portanto, a terminologia acompanhante terapêutico ainda não havia sido designada para nomear tal prática influenciada pelo contexto da reforma psiquiátrica. No primeiro livro sobre o tema, por Mauer e Resnizky (1985), e na dissertação de Reis Neto (1995), surgiu a versão de que o AT proposto atualmente no tratamento dos portadores de sofrimento mental teve sua origem na Argentina, no final da década de 1960 e início da década de 1970, sob o nome de amigo qualificado e sob o enfoque de um grupo multidisciplinar que constituiu o CETAMP (Centro de Estudos e Tratamento de 
Abordagem múltipla em Psiquiatria, Buenos Aires), dirigido pelo Dr. Eduardo Kalina. A proposta do CETAMP era marcada por uma articulação mais democrática dos saberes e técnicas específicas de cada um dos membros do grupo que prestava atendimentos a pacientes graves; preservava-se o trabalho em equipe, excluindo a ideia do saber hierarquizado. Esse trabalho era feito sem vinculação a hospitais psiquiátricos, mas em associação com clínicas ou comunidades terapêuticas, sendo que os atendimentos eram feitos pelos profissionais tanto dentro quanto fora das instituições. Segundo Porto e Sereno (1991), nos anos 70, também na Argentina, o termo atendente terapêutico substituiu o amigo qualificado. Sobre essa mudança:

A nomenclatura amigo qualificado passou a ser discutida por aqueles profissionais que, com experiência nesse trabalho, perceberam que o termo amigo sugeria equivocadamente um vínculo de simetria entre pacientes e profissionais. A relação pensada em termos de igualdade, conforme o laço afetivo criado através da amizade, não possibilitava a clareza e delimitação dos papéis. Assim, esses profissionais passam a ser chamados de atendentes terapêuticos e posteriormente de acompanhantes terapêuticos (Santos, Nogueira \& Dutra, 2002, p. 100-101).

No final dos 70 e início dos 80 , a designação de tal dispositivo clínico foi tida como acompanhantes terapêuticos. Essa passagem é descrita por Nelson Carrozzo (1991) como um recurso usado pela equipe do Instituto $A$ Casa que, com sua experiência em instituições psiquiátricas asilares e no sentido inverso à proposta de internações, faziam uso de dois recursos. $\mathrm{O}$ primeiro apontava para uma nova mudança de nomenclatura, que se firmou a partir da década de 1980 para acompanhante terapêutico, e que permanece até hoje." [...] Termo não mais definido por continência oferecida amizade, mas sim, por uma ação, uma ação junto à outra pessoa: o acompanhar" (Carrozzo, 1991, p. 32). Esse primeiro recurso surgiu com o intuito de não limitar o atendimento ao período de funcionamento do hospital-dia que era das 9 às 17 horas. $\mathrm{O}$ segundo recurso salientava a importância da terapia familiar para a evolução do tratamento. A equipe do Instituto A Casa, desde seu surgimento, usou a teoria psicanalítica como base para o trabalho de toda a clínica, inclusive dos acompanhantes terapêuticos.

Chegando a uma abordagem mais atual, a questão o que éo $A T$ ?, formulada por Carvalho (2004), faz-se presente em estudos acadêmicos contemporâneos, já que éo termo usado atualmente. Após o $1^{\circ}$ Encontro Paulista de Acompanhantes Terapêuticos, em 1989, começou-se a traçar características que delineiam esse dispositivo como, por exemplo, referir-se a uma clínica que ocorre no cotidiano 
do paciente e de setting variável. Por vezes, havendo situações em que tanto o acompanhante quanto o acompanhado podem se deparar com pessoas que fazem parte da vida particular de cada um deles, como também de diferentes níveis da rede social, devendo, assim, nessas circunstâncias, manter sigilo e preservar a privacidade do paciente. Outra característica é que geralmente o paciente é acompanhado mais de uma vez por semana, em um período maior que nas psicoterapias, e que o acompanhante terapêutico está atrelado a uma equipe, ou seja, nunca trabalhando sozinho (Carvalho, 2004).

Uma formalização mais recente do AT, referente a elementos que demarcam seu percurso histórico, o insere como um dispositivo que é, em grande parte, exercido por estudantes de Psicologia, "propondo uma reorientação do fazer simplesmente para o fazer sustentado por um saber" (Guerra \& Milagres, 2005, p. 63). A supervisão e a orientação não se limitam mais ao médico, mas também a outros profissionais, e o uso da palavra torna-se um recurso de operação fundamental, em vez da contenção física ou mecânica. Há, consequentemente, uma busca de um aparato teórico mais consistente para sustentação de tal prática e o diálogo com outras vertentes teórico-profissionais que não apenas a do saber psiquiátrico (Guerra \& Milagres, 2005).

Com base nesses elementos, que demarcam a história do AT, podemos levantar várias questões como: o que seria esse fazer sustentado por um saber? Ou ainda, o que seria esse encontro com pessoas, tanto por parte do acompanhado como por parte do acompanhante? Ou qual o lugar da equipe multidisciplinar em relação a tal dispositivo clínico? O referencial psicanalítico, que prioriza o uso da palavra, pode nos ser útil aqui?

Por se tratar de uma prática móvel, de setting não determinado, torna-se possível o encontro com muitos, sejam eles íntimos, conhecidos ou não, seja um profissional da equipe multidisciplinar ou um atendente da papelaria e, esses muitos é que constituem a Rede Terapêutica.

Acreditamos que o AT é uma modalidade de intervenção inserida em uma Rede Terapêutica, com o objetivo de ampliar a atenção para além das fronteiras e do acompanhamento medicamentoso subsequente, atuando justamente nesse hiato. $\mathrm{O}$ conceito de Rede Terapêutica veio substituir os antigos enfoques - trabalhos inter ou multidisciplinares - propondo uma nova compreensão da atenção em Saúde Mental (Generoso et al., 2002, p. 8).

A nomenclatura "rede terapêutica", justifica-se por possibilitar ao psicótico a construção de novas referências que não sejam apenas os profissionais 
da equipe multidisciplinar. Dessa forma, a construção de laços sociais e emocionais do paciente não se restringe aos serviços substitutivos dos hospitais psiquiátricos.

Porém, para que haja possibilidade de construção de novas referências para o paciente em AT, não basta que esse dispositivo clínico se sirva de um setting variável e, por conseguinte, de uma Rede Terapêutica. É a partir desse ponto que o acompanhante terapêutico pode vir a servir-se da teoria psicanalítica como um saber, para orientação de sua clínica. Não um saber encarnado, aquele que é previsto, que já se sabe de antemão, ou seja, o saber do mestre (Lacan, 1992). A maneira com que um sujeito constrói certo laço com o Outro $^{4}$ é de fundamental importância para questionar como manejar esse Outro intransigente, muito presente na relação com a psicose. A representação do Outro na psicose pode ser invasiva demais para o sujeito, uma vez que nela o Outro sabe, dita as normas, mostra-se de forma imperativa, inflexibilizada, e compactuar com essa posição que o próprio psicótico nos coloca é ir na contramão de seu tratamento.

Portanto, saber-fazer em detrimento da clínica do AT na psicose, conforme a teoria psicanalítica nos elucida, trata-se de manejar o lugar ocupado pelo acompanhante terapêutico. Conforme o acompanhante terapêutico vale-se do "saber-não-saber" é que se possibilita à psicose testemunhar seu discurso (Lacan, 2002b). O testemunhar pode implicar em fazer valer o discurso do psicótico, para que haja, a partir de então, a possibilidade de construção, de significação em que antes não advinha sentido algum, como nos foi demonstrado por Freud no caso Schreber (Freud, 1996). Neste, a partir de seu testemunho é que seu delírio de emasculação passa a significar-lhe algo (ser copulado por Deus para gerar uma nova raça para povoar a Terra), "[...] é a função real do pai na geração que vemos surgir sob uma forma imaginária” (Lacan, 2002a, p. 243). O fato de sua falta de filhos, conforme afirmou Freud (1996, p. 88-89), foi o motivo de sua enfermidade, de sua "fantasia feminina de desejo"; portanto, há uma vinculação entre seu delírio e o que ocasionara sua moléstia. A questão é menos a de classificar o delírio como um fenômeno estrutural do que a de indagar como ele aparece e qual o valor de seu testemunho. "Em tudo que é da ordem do testemunho, há sempre empenho do sujeito, e luta virtual a que

\footnotetext{
O termo "laço com o Outro" não se trata simplesmente da capacidade do sujeito de se relacionar com o social, ou seja, com os outros: mãe, padrasto, pastores, etc.; nem mesmo com as instituições: família, Igreja, hospital, entre outras. A relação que o sujeito estabelece com os outros e com as instituiçōes, ou melhor, o lugar que o sujeito designa ao outro é nomeado por Lacan de Outro. Conforme Lacan: "[...] No interior da noção de comunicação enquanto generalizada, especifico o que é a palavra enquanto falar ao outro. É fazer falar o outro como tal. Esse outro, nós o escrevemos [...] com A maiúsculo”, pois Lacan refere-se ao Outro absoluto - Absoluto, uma vez que o outro é falado, dito em palavras por meio de uma mensagem a alguém, a um outro qualquer, esse outro falado torna-se Absoluto, "[...] ele é reconhecido, mas [...] não é conhecido" (Lacan, 2002a, p. 48-49).
} 
o organismo está sempre latente" (Lacan, 2002a, p. 51). Foi a possibilidade de testemunhar seu próprio delírio que tornou possível a Schreber significar, mesmo que de forma imaginária, a sua relação com a paternidade.

A partir de então, esse distanciamento do lugar que o próprio psicótico refere-se ao Outro passa a ser esvaziado de sentido. Assim, ele pode passar a demandar uma visita à família, uma atividade, um profissional da equipe de saúde mental, etc.

$\mathrm{O}$ setting e a rede terapêutica funcionam como ferramentas interessantes no AT, desde que sejam construídos juntamente com o paciente e de forma gradativa no decorrer do tratamento. É ocupando o lugar de testemunha do percurso que o próprio paciente vai traçando, que a relação do Outro na psicose passa a ser trabalhada na clínica do AT.

\section{Acompanhamento terapêutico em Betim}

O AT em Betim foi implantado por uma parceria entre as instituiçôes de saúde pública e de saúde mental, como o Cersam (Centro de Referência de Saúde Mental), a Moradia Protegida de Betim, além da instituição acadêmica PUC Betim (Pontifícia Universidade Católica de Minas Gerais, Campus Betim). Na Universidade, o responsável pelas disciplinas de Psicopatologia e Nosologia, do sexto período do curso de Psicologia, que estabelece o estágio e supervisiona o trabalho dos alunos, é o professor Renato Diniz 5 . No Cersam e na Moradia Protegida, a responsável pela coordenação e supervisão dos estagiários é Cláudia Generoso ${ }^{6}$.

Esses estágios aconteceram em duas fases: na primeira, em 2000, caracterizou-se como um estágio curricular com duração de quatro meses, tendo como participantes alunos do $6^{\circ}$ período de Psicologia vinculados à disciplina de Psicopatologia. Não se tratava de um estágio de entrevistas a pacientes psiquiátricos com a finalidade de estudar hipóteses diagnósticas. Os alunos tiveram um contato mais direto com os pacientes, na maioria das vezes psicóticos indicados pela equipe de saúde mental do Cersam ao AT, enquanto trabalhavam o meio de condução de um tratamento. A outra fase

\footnotetext{
Doutor em educação pela Universidade Federal de Minas Gerais (2008) e mestre em Psicologia Social pela Universidade Federal de Minas Gerais (2000). Atualmente é professor titular de Psicopatologia, Nosologia e Elaboração de Monografia da Pontifícia Universidade Católica de Minas Gerais e preceptor da Residência em Psiquiatria do Instituto Raul Soares/ Fhemig. Supervisor do CAPS (Centro de Atenção psicossocial) da Prefeitura municipal de Santa Luzia-MG.

6 Mestre em Psicologia pela Faculdade Filosofia Ciências Humanas (2006), graduado em Psicologia pela Pontifícia Universidade Católica de Minas Gerais (1990). Atualmente é técnico da saúde: psicóloga da Prefeitura Municipal de Betim, atuando no Centro de Referência em Saúde Mental e Moradia Protegida em Saúde mental; pesquisadora da Universidade Federal de Minas Gerais.
} 
desse estágio ocorreu também no Cersam e na Moradia Protegida, podendo ser caracterizado como um estágio de extensão, com duração de um ano, 20 horas semanais remuneradas e contando com alunos a partir do $8^{\circ}$ período de Psicologia, sendo o AT uma função nesse estágio, entre outras que são exercidas pelos alunos (Generoso \& Diniz apud Nogueira, 2007) ${ }^{7}$.

Também na graduação, como estágio regular, foi implementado o AT na Saúde Mental infanto-juvenil. Nesse estágio, os alunos trabalhavam no Cersami (Centro de Referência em Saúde Mental Infanto-juvenil) que lida com casos de autismo e de psicose infantil. As práticas consistiam, primeiramente, em oficinas terapêuticas e, só posteriormente, em AT. Os principais elementos trabalhados no estágio no Cersami eram o desenvolvimento da relação entre a mãe e a criança, bem como a demanda de inserção escolar. Há uma rede específica para a criança e o adolescente, com esporte, lazer, cultura, que é usada no AT infanto-juvenil (Guerra apud Nogueira, 2007) ${ }^{8}$.

Em Betim, os acompanhantes terapêuticos são, portanto, estudantes do curso de Psicologia que desenvolvem essa função em instituições psiquiátricas.

Em relação às indicações para AT em geral, são feitas a pacientes que os "vínculos sociais se apresentam muito rompidos, difíceis de estabelecer laços" (Generoso apud Nogueira, 2007). Trata-se de pacientes que não se aderem a nenhuma atividade proposta pela instituição, além de permanecerem isolados, tanto no meio familiar quanto no institucional.

Outro ponto importante é o efeito causado pelo AT não somente no psicótico, mas também no acompanhante, que inicialmente vem com "uma vontade muito grande de social", ou seja, de propiciar ao psicótico circular normalmente pelo shopping, praça, cinema, locais para prática de esportes, porém isso nem sempre é possível, e os acompanhantes terapêuticos vão, portanto, deparando-se com as limitações de cada caso e, consequentemente, suas limitações como sujeitos desejantes. "Às vezes, um paciente que só fica em casa, não sai de casa, se ele consegue ir a uma consulta e começa a ir às

\footnotetext{
Entrevista concedida por Cláudia Generoso e Renato Diniz para o desenvolvimento da pesquisa Acompanhamento terapêutico na psicose: um percurso histórico na Grande BH, amparada pela UFMG/2006 e usada como um recurso metodológico para o desenvolvimento de parte da dissertação $O$ acompanhamento terapêutico na psicose: possibilidades de uma orientação analítica.

8 Entrevista concedida por Andréa Máris Campos Guerra para o desenvolvimento da pesquisa Acompanhamento terapêutico na psicose: um percurso histórico na Grande BH, amparada pela UFMG/2006 e usada como um recurso metodológico para o desenvolvimento de parte da dissertação $O$ acompanhamento terapêutico na psicose: possibilidades de uma orientação analítica. Doutora em Teoria Psicanalítica pela Universidade Federal do Rio de Janeiro, com período de estudos aprofundados na Université de Rennes II (2007), mestra em Psicologia pela Universidade Federal de Minas Gerais (2000), graduada em Direito pela Universidade Federal de Juiz de Fora (1994), graduada em Psicologia pelo Centro de Ensino Superior de Juiz de Fora (1995) e atualmente professora adjunta do Departamento de Psicologia da UFMG.
} 
consultas, já é um efeito interessante" (Generoso apud Nogueira, 2007).

Portanto, podemos perceber que o papel do acompanhante terapêutico nem sempre está claro para ele mesmo, principalmente enquanto ele projeta no paciente os próprios anseios sociais. Mas, por outro lado, o papel do acompanhante terapêutico pode estar muito bem colocado quando orientado sob o efeito que sua manobra clínica poderá causar no psicótico, como nos traz Generoso, citado por Nogueira (2007), em relação ao revezamento dos acompanhantes terapêuticos para minimizar o efeito persecutório de um paranoico da Moradia Protegida de Betim, que entrava numa relação persecutória com qualquer um deles que ficasse por mais tempo no caso.

Além de supervisões semanais nas instituições e na Universidade, a não especificação de um acompanhante terapêutico para cada caso é uma manobra muito usada na Moradia Protegida de Betim.

Apesar dos impasses trazidos pela implantação do AT nas instituições (atritos na equipe, pouco tempo para estabelecer laços transferenciais ${ }^{9}$ entre o acompanhante terapêutico e o paciente, rotatividade dos acompanhantes, dificuldades da política local na distribuição de bolsas de remuneração aos estagiários cedidas pela prefeitura), o AT na cidade vem sendo referência tanto no tratamento da saúde mental quanto em relação ao aprendizado da clínica da psicose pelos alunos (Diniz apud Nogueira, 2007).

\section{AT em Belo Horizonte}

Em Belo Horizonte, o AT teve seus primeiros sinais em meados da década de 1970, ao mesmo tempo em que as comunidades terapêuticas (Centro Psicoterapêutico e Centro Terapêutico Santa Margarida) foram implantadas na capital.

No Centro Terapêutico Santa Margarida, que já se extinguiu, o AT era feito por estudantes, em geral de Psicologia e Terapia Ocupacional, e conduzido por Clóvis Bicalho e Stélio Lage Alves ${ }^{10}$, e por Consuelo Guimarães e Ana Maria Castro Nascimento ${ }^{11}$. Essa prática clínica era fortemente influenciada pelo AT da comunidade terapêutica Clínica Pinel, em Porto Alegre, e pelo CETAMP, residido na Argentina (Buenos Aires). Tratava-se de um dispositivo terapêutico caracterizado pelo atendimento individual, embasado na teoria

\footnotetext{
9 Com base na da maneira que um sujeito estabelece a relação com o Outro é que podemos entender como ele poderá manifestar-se na transferência, ou seja, estabelecer um laço transferencial.

${ }_{10}$ Psiquiatras e psicanalistas em 1970.

11 Terapeutas ocupacionais em 1970.
} 
psicanalítica, atrelado a intervenções na família dos pacientes. As funções do AT, entretanto, não se vinculavam a um fazer específico como as funções dos psiquiatras, dos terapeutas ocupacionais, dos psicanalistas e dos psicólogos que integravam a equipe multidisciplinar (Greco, 2000).

Esse estagiário que senta com o paciente para ver televisão não exercia a função específica de um terapeuta ocupacional. Tinha uma atividade a fazer, mas ele não estava vinculado a um fazer específico. Ele não atendia o paciente no consultório, mas, por exemplo, ele se interava com o paciente na visita, mediava a visita na relação do paciente com a sua família, ali no lugar de instituição e permitindo que as coisas não tomassem um rumo muito desfavorável, ou seja, ele não atendia no consultório e nem propunha uma atividade com fins específicos (Greco apud Nogueira, 2007) ${ }^{12}$.

Apesar da prática de AT começar a ser difundida na capital, segundo Greco (2000), houve dois momentos que contribuíram para que essa prática perdesse certo lugar no tratamento da psicose. O primeiro momento, na metade dos anos 80 , ocorreu pela patrulha lacaniana ${ }^{13}$, que restringia os meios de tratamento da psicose, muito criticados na capital caso fossem conduzidos fora do setting clássico do psicanalista, o consultório. O segundo momento, na década de 1990, ocorreu com as oficinas terapêuticas, dispositivo usado nas instituições psiquiátricas públicas advindas da prática antimanicomial, quando foi então questionado o trabalho dos psicanalistas e dos acompanhantes terapêuticos que tinham como referência a ética psicanalítica, tida como "alienada diante do pragmatismo social que ganhava força e ocupava o campo da clínica" (Greco, 2000).

Em 1995, segundo Generoso et al. (2002), foi constituída, em Belo Horizonte, a instituição psiquiátrica privada Clínica Urgentemente, sob a influência da reforma psiquiátrica e, consequentemente, "com o objetivo de sustentar o paciente portador de transtorno mental grave, em crise, fora da estrutura hospitalar”. Em 1996, conveniados com a CASSI (caixa de assistência dos funcionários do Banco do Brasil) e sob a influência da experiência clínica do antigo Instituto A Casa de São Paulo, a Clínica Urgentemente construiu

\footnotetext{
${ }^{12}$ Entrevista concedida por Musso Greco para o desenvolvimento da pesquisa Acompanhamento terapêutico na psicose: um percurso histórico na Grande BH, amparada pela UFMG/2006 e usada como um recurso metodológico para o desenvolvimento de parte da dissertação $O$ acompanhamento terapêutico na psicose: possibilidades de uma orientação analítica. Doutorando em Ciências da Saúde (Faculdade de Medicina/UFMG), mestre em Psicologia pela Fafich/UFMG (2000), especialista em Saúde Mental pela Escola de Saúde Pública de Minas Gerais (1994), graduado em Medicina pela UFMG (1984), fez residência médica em Psiquiatria no Hospital Raul Sores/Fhemig (1986).

${ }^{13}$ Termo usado por Greco, que faz referência ao modo como os estudiosos da psicanálise lacaniana em Belo Horizonte a interpretavam naquela época, delimitando o seu campo de atuação.
} 
um projeto com vistas à desospitalização psiquiátrica dos pacientes dela, sendo que um dos dispositivos usados para tal finalidade foi o AT. Ainda conforme Fonseca, em 1998, foi inaugurada pela Clínica Urgentemente a primeira moradia protegida de Minas Gerais, intitulada Nossa Casa, em que seus moradores eram psicóticos que necessitavam de uma resposta no social (errância, isolamento, dificuldades de convivência, impossibilidade de retorno à convivência familiar). Nesta, participavam a própria equipe da Clínica Urgentemente como intermediadora e agenciadora das relações do novo grupo formado por seus moradores, um coordenador (função de um membro da equipe), um psiquiatra de referência e, em um primeiro momento, foi acionado um acompanhante terapêutico para cada morador.

Os motivos das indicações foram dificuldades de adaptação da própria rotina de forma independente como também problemas na administração dos bens pessoais (manuseio do dinheiro, noções de higiene, entre outras). Segundo os resultados alcançados, quatro dos nove moradores, em um percurso de três anos na Nossa Casa, voltaram a residir com as famílias e um foi residir com uma família substitutiva, os demais permaneceram na Moradia Protegida. Essa casa se tornou referência para os moradores. Em dois casos, em decorrência de conflitos familiar/social, houve retorno de curta permanência à Moradia. O poder contratual, como a capacidade de fazer escolhas, a tolerância em relação às decisões do grupo e a melhora na condução dos relacionamentos interpessoais dentro da moradia, melhorou significativamente após o AT. Também houve uma melhora significativa em relação à circulação pela cidade, que foi considerada ampliada em comparação ao início de todo o processo do trabalho de equipe proposto pela Nossa Casa. Apenas três dos moradores continuaram com o AT, sendo que os demais se tornaram independentes desse dispositivo para continuar a transitar pela cidade. Ainda em 1998, a Clínica Urgentemente criou um curso de formação de dois anos para melhor preparação dos profissionais (acompanhantes terapêuticos).

Houve uma grande importância do trabalho proposto pela Clínica Urgentemente no tratamento do portador de sofrimento mental, que trouxe para Belo Horizonte "uma conciliação teórica do campo social e do campo psíquico, que permitem perspectivas de organização de serviços como a do trabalho em rede e a práxis de uma clínica de muitos" (Greco, 2000). A Clínica Urgentemente influenciou fortemente a valorização de outros campos de conhecimento para além da psiquiatria e da psicanálise, no tratamento do portador de sofrimento mental, como a terapia ocupacional, a assistência social, além da vinculação de segmentos da rede pública para o auxílio nos tratamentos. 
A partir de então, revigorou-se, em Belo Horizonte, o dispositivo AT.

$\mathrm{O}$ analista da cidade, $\mathrm{o}$ analista cidadão, a psicanálise aplicada, a clínica ampliada da psicose, a clínica da contribuição italiana, dos psicanalistas italianos, vieram para Belo Horizonte como uma autorização para uma prática ampliada da psicanálise, onde o acompanhante terapêutico, as oficinas terapêuticas, o hospital-dia, os grupos com pacientes psicóticos ganharam uma possibilidade de serem realizados (Greco apud Nogueira, 2007).

O AT, em Belo Horizonte, começou a ser implantado junto com os serviços substitutivos dos hospitais psiquiátricos, o que se configurou como uma prática destinada ao movimento trazido pela reforma psiquiátrica.

Com Programa de Desospitalização Psiquiátrica (PDP), implantado pela Prefeitura de Belo Horizonte, juntamente com a implantação das Moradias Protegidas, do uso do dispositivo clínico AT e das parcerias com as universidades (Newton Paiva, em 2000, e Centro Universitário Fumec, em 2001):

Foram desospitalizados 120 pacientes dos 700 que precisavam ser. Pacientes que viviam em hospitais psiquiátricos pelos mais variados motivos como abandono familiar, desfavorável situação econômica, perda do vínculo social com família, amigos, trabalho, sendo que alguns desses encontravam-se por mais de quinze anos internados (Greco apud Nogueira, 2007).

O estágio de AT foi proposto pela Newton Paiva pelo curso de Psicologia, como um projeto de extensão, juntamente com a rede de saúde mental do Município de Belo Horizonte e o PDP. Não se tratava de um estágio curricular. Ao todo, 20 bolsas foram custeadas para o desenvolvimento desse estágio exercido por alunos que cursavam a disciplina de Psicopatologia, ministrada por Guerra. A bolsa equivalia a 20 horas semanais de estágio. Inicialmente o acompanhamento terapêutico acontecia dentro dos hospitais psiquiátricos, onde os acompanhantes terapêuticos encontravam dificuldades das mais diversas, a maioria delas de ordem institucional. Em um segundo momento do tratamento, o AT acontecia na rua, na própria casa e, ou, serviço do paciente, ou em alguma atividade de lazer proposta com a finalidade de reinserção social. A indicação era feita para usuários da rede pública de saúde mental, com longo período de internação e que estavam, pelo $P D P$, voltando para suas residências ou, em alguns casos, para serviços residenciais terapêuticos (Guerra apud Nogueira, 2007).

Já no Centro Universitário Fumec (Fundação Mineira de Educação e Cultura), em 2001, a implantação do estágio de AT ocorreu por uma parceria 
com a Prefeitura Municipal, pela Coordenação de Saúde Mental. O estágio tinha a ideia inicial de trabalhar com as famílias dos pacientes do Cersam, porém havia uma demanda por parte dos trabalhadores da rede pública representados, na época, pela coordenação do Cersam Pampulha e que teria, como alvo, pacientes tidos como "cronificados" 14 , alguns desses pacientes precisavam de até mesmo serem buscados e levados pela instituição. As indicaçôes de AT para tais casos tiveram a finalidade de fazer o Cersam funcionar como passagem, o que é demarcado como uma ideia original desse tipo de dispositivo da rede pública de saúde mental. Havia supervisões semanais com Guerra na Universidade, além da participação dos estagiários (acompanhantes terapêuticos) nas reuniōes, também semanais, da equipe do Cersam, porém o estágio não era remunerado. Os projetos de AT, tanto viabilizados pela Universidade Newton Paiva quanto pela FUMEC, eram orientados pela teoria psicanalítica lacaniana.

$\mathrm{Na}$ Casa Frend, o AT é um dispositivo uzado desde 1996 até hoje, sendo que os acompanhantes terapêuticos (em sua maioria, psicólogos eenfermeiros, mas também terapeutas ocupacionais que já estagiaram na instituição quando graduandos) não são contratados e sim indicados a alguns pacientes que passam por aquela casa. É um serviço contratado pela família do paciente em questão, nesse caso, um serviço particular, acionado mediante a indicação do profissional da Casa Freud à família. Tal indicação é feita para casos em que o paciente precise de mediação ao sair da internação na instituição psiquiátrica para sua casa. Tecnicamente, referente a esse tipo de indicação, o trabalho do acompanhante terapêutico é vinculado à equipe da Casa Freud ou a algum profissional que esteja conduzindo o caso fora da instituição. Já nas Universidades Newton Paiva e FUMEC, atualmente, o AT vem perdendo certo lugar em relação à sua vinculação como estágio curricular, apesar dos ganhos relacionados a produções de monografias de conclusão de curso sobre o tema (Guerra apud Nogueira, 2007).

Alguns percalços podem ter contribuído para tal fator, como o corte de bolsas que, aos poucos, foi sendo feito pela Newton Paiva e pelo alto custo de um estágio curricular, e ainda, paralelamente, pelo desinteresse da Prefeitura de Belo Horizonte e do Serviço Municipal, diante dos problemas criados pelo dispositivo clínico AT em relação à sua inserção nas instituições (Milagres apud Nogueira, 2007) ${ }^{15}$.

\footnotetext{
${ }^{14}$ Pacientes com alto índice de reincidência em relação ao Cersam Pampulha e pacientes que o frequentavam semanalmente durante anos.

${ }^{15}$ Entrevista concedida por Andréa Milagres para o desenvolvimento da pesquisa Acompanhamento terapêutico na psicose: um percurso histórico na Grande BH, amparada pela UFMG/2006 e usada como um recurso metodológico para o desenvolvimento de parte da dissertação $O$ acompanhamento terapêutico na psicose: possibilidades de uma orientação analítica. Mestra em Psicologia pela Universidade Federal de Minas Gerais (2003), especialista em Saúde Mental pela Escola de Saúde Pública de Minas Gerais (1995), graduada em Psicologia pela Pontifícia Universidade Católica de Minas Gerais (1988). Atualmente é coordenadora de estágios do curso de Psicologia e do Curso de Especialização em Clínica Psicanalítica nas Instituiçôes de Saúde da Pontifícia Universidade Católica de Minas Gerais (campus Betim).
} 
A função do AT perdeu-se nas instituições em que estava sendo implantada como dispositivo clínico. Tarefas de muita responsabilidade passaram a ser incumbidas aos acompanhantes terapêuticos (alunos), sem que tivessem a ver com o trabalho de AT. Inicialmente, cada aluno era responsável pelo AT de dois pacientes, mas, no decorrer do estágio, os acompanhantes terapêuticos passaram a ser mais da instituição do que dos próprios pacientes. A partir de então, o acompanhante terapêutico passou a ser uma figura mais presente dentro da instituição do que fora dela (Milagres apud Nogueira, 2007). Outro ponto não menos importante que nos traz Milagres é que existe uma questão financeira que permeia toda a situação do aluno de faculdade particular. Muitos deles precisam trabalhar durante a semana para pagar as mensalidades, portanto existem períodos em que as turmas de estágio de AT não são completadas, não se obtendo o número mínimo de alunos para o exercício do estágio, principalmente após o corte das bolsas.

Outro programa muito interessante que também trabalha com o dispositivo AT e que foi implantado em Belo Horizonte por meio da parceria entre a Universidade Newton Paiva o o Tribunal de Justiça de Minas Gerais é o PAI-PJ (Programa de Atenção Interdisciplinar ao Paciente Judiciário). Em uma prática interdisciplinar, os alunos de Psicologia atuam na assistência à saúde mental tanto dos pacientes judiciários quanto na assistência aos familiares destes. $\mathrm{O}$ programa promove o tratamento em saúde mental, na rede pública de saúde de Belo Horizonte, por meio de medidas de segurança estabelecidas pelo juiz no que diz respeito ao então paciente infrator. $\mathrm{O}$ AT é feito tanto por estudantes de Psicologia da Universidade Newton Paiva como também por profissionais graduados da própria instituição, e entra na construção de um projeto clínico juntamente com outros dispositivos oferecidos pela rede pública.

\section{Avanços e impasses}

Pode-se perceber como atualmente o AT vem sendo acompanhado por uma abordagem teórica. Na pesquisa de Carvalho (2004) com os acompanhantes terapêuticos inscritos no $3^{\circ}$ Encontro Paulista de Acompanhantes Terapêuticos e $1^{\circ}$ Encontro Nacional de Acompanhantes Terapêuticos, constatou-se que 69\% vinculavam seu trabalho à psicanálise, 4,8\% ao psicodrama e 3,6\% à "abordagem junguiana". Desses profissionais, $52,4 \%$ dividiam-se em graduados e pós-graduados. Em Minas Gerais, confere-se, portanto, que os acompanhantes terapêuticos, em maior parte, são estudantes de Psicologia que se vinculam ao trabalho da rede pública de saúde mental, e as supervisões e orientações advindas das instituições também são norteadas por um saber teórico, no caso, também em maior escala, a psicanálise de orientação lacaniana. 
Outro ponto que pode ser considerado como um avanço é o fato de que o AT não se limita à finalidade de desospitalização psiquiátrica, como podemos perceber em seu percurso histórico. Há certa demanda institucional para lidar com os pacientes cronificados, mas há também uma demanda social, seja da família, da escola ou da instituição, ou ainda demandas do próprio paciente em relação ao acompanhante terapêutico. Demandas para trabalhar, para participar de atividades de lazer, para retomar atividades interrompidas, para melhorar a frequência escolar, para aderir a atividades propostas dentro das instituições, para não levar tão a sério o que é dito pelo outro, enfim, o AT é acionado diante de impasses consequentes da clínica da psicose como ruptura do laço social ${ }^{16}$ e da institucionalização ${ }^{17}$.

Se, por um lado, o acompanhante terapêutico entra para lidar com certos impasses na clínica da psicose, como já mencionado acima, por outro, ele cria novos impasses caso não seja bem orientado por um saber teórico.

Aceitar a indicação do paciente ao AT em estado "bruto", em que o acompanhante terapêutico tenta responder a toda demanda dos pacientes, de suas famílias e até mesmo da equipe de saúde a qual o paciente está vinculado, cria alguns problemas acerca da clareza de delimitações das funções da prática do profissional que se misturam a funções que poderiam ser exercidas pela própria família do paciente e pela equipe. Problemas como o grande envolvimento na família do paciente (às vezes, levado à posição de espião), ocupando a função de babá na ausência da família ou como uma espécie de quebra-galho para tarefas que poderiam ser resolvidas sem a sua presença. Além de afastar o envolvimento da família e da equipe de saúde mental no tratamento, põe em risco sua relação com o psicótico, uma vez que o acompanhante terapêutico passa a ser uma referência quase que exclusiva para o sujeito, por não se servir da rede terapêutica. Dessa forma, além de não possibilitar a construção de novos laços sociais para o psicótico, o acompanhante terapêutico pode contribuir para o desencadeamento persecutório no paciente. Conforme Freud (1996, p. 73), em relação ao delírio de perseguição, geralmente o perseguidor é alguém que foi muito amado, mas, devido à resistência, transformou esse amor em um sentimento hostil, o que aponta para capacidade de transferência na psicose apesar de ser em sua vertente negativa. Portanto não se torna aconselhável,

\footnotetext{
${ }^{16}$ Na psicose, para Freud, a realidade é repudiada e, posteriormente, há uma tentativa de substituí-la, “[...] o novo e imaginário mundo externo de uma psicose tenta colocar-se no lugar da realidade - um fragmento diferente daquele contra o qual tem de defender-se -, e emprestar a esse fragmento uma importância especial e um significado secreto [...]" (Freud, 1996, v. 19, p. 209).

${ }^{17}$ São pacientes que passam a depender da instituição psiquiátrica. Quando o paciente encontra-se vinculado a ela de tal forma que dificulta sua aderência a outros serviços e atividades, além de causar problemas ao paciente, que rompe sua relação com o lado de fora da instituição, podem ocasionar problemas de ordem burocrática (superlotação) ou mesmo de ordem financeira nas instituiçōes.
} 
no tratamento da psicose, focar a clínica em uma só referência, em um só profissional. Daí a importância da rede terapêutica no AT.

Outro problema, não muito raro, são os atravessamentos em seu trabalho pela equipe da qual ele faz parte. Estratégias e acontecimentos sobre sua prática junto ao psicótico são levados à equipe, que as usam em simples conversas com o paciente ou nas próprias sessões de atendimento clínico, de tal forma que a posição da equipe e do próprio acompanhante terapêutico tornam-se invasivas para o sujeito.

$\mathrm{O}$ setting ambulante e a rede terapêutica se configuram, portanto, como suporte para a clínica do AT, uma vez que contribuem para que o acompanhante terapêutico não se torne uma referência maciça para a psicose. O acompanhante terapêutico, portanto, faz parte de uma rede terapêutica, o que possibilita uma transferência múltipla, não localizada em um único profissional.

Uma de suas principais funções é posicionar-se como mais um dos profissionais da equipe multidisciplinar. É importante deixar claro sua posição clínica para não dar margens à dimensão persecutória presente na psicose. $\mathrm{O}$ acompanhante terapêutico não é um amigo, um conselheiro, um analista, e sim aquele que acompanha o psicótico em suas construçôes.

Esses são alguns avanços e impasses atuais na saúde mental, no que concerne ao dispositivo clínico AT em Minas Gerais, levantados tanto a partir de seu percurso histórico quanto clínico.

\section{Referências}

Berger, E. et al. (1991). História. In: A. Morettin et al. (org.). A rua como espaço clínico. (p. 17-22). São Paulo: Escuta.

Carrozzo, N. L. M. (1991). Campo de criação, campo terapêutico. In: A. Morettin et al. (Org.). A rua como espaço clínico. (p. 31-40). São Paulo: Escuta.

Carvalho, S. (2004). Acompanhamento terapêutico, que clínica é essa? São Paulo: Annablume.

Cauchick, M. P. (2005). Sorrisos inocentes e gargalhadas horripilantes: intervençôes no acompanhamento terapêutico. São Paulo: Annablume. 
Freud, S. (1969). A dinâmica da transferência. In: S. Freud. Edição standard brasileira das obras psicológicas completas de Sigmund Freud.(v. 12, p. 107-119). Rio de Janeiro: Imago. (originalmente publicado em 1912).

Freud, S. (1976). A perda da realidade na neurose e na psicose. In: S. Freud. Edição standard brasileira das obras psicológicas completas de Sigmund Freud. (v. 19, p. 203-205). Rio de Janeiro: Imago. (originalmente publicado em 1924).

Freud, S. (1996). Notas psicanalíticas sobre um relato autobiográfico de um caso de paranoia (dementia Paranoides). In: S. Freud. Edição standard brasileira das obras psicológicas completas de Sigmund Freud (v. 12, p. 15-89). Rio de Janeiro: Imago. (originalmente publicado em 1911).

Generoso, C. M. et al. (2002). O projeto de trabalho da clínica urgentemente: novos dispositivos aplicados na ampliação da clínica em saúde mental e suas interlocuções com o campo social. A rede: clínica ampliada em saúde mental, 1 (1), 7-17.

Greco, M. G. (2000). Acompanhante terapêutico: o guia das cidades invisiveis. Belo Horizonte: Mimeo.

Guerra, A. \& Milagres, A. (2005). Com quantos paus se faz um acompanhamento terapêutico? Contribuições da psicanálise a essa clínica em construção. Estilos, 10 (19), 60-83.

Lacan, J. (1992) O mestre e a histérica. In: J. Lacan. O seminário, livro 17: o avesso da psicanálise. (p. 27-36). Rio de Janeiro: Jorge Zahar.

Lacan, J. (2002a). O outro e a psicose. In: J. Lacan. O seminário, livro 3: as psicoses. (p. 39-54). Rio de Janeiro: Jorge Zahar.

Lacan, J. (2002b). Secretários do alienado. In: J. Lacan. O seminário, livro 3: as psicoses. (p. 235-243). Rio de Janeiro: Jorge Zahar.

Mauer, S. \& Resnizky, S. (1985). Acompanhantes terapêuticos e pacientes psicóticos: manual introdutório a uma estratégia clínica. São Paulo: Papirus.

Nogueira, B. A. (2007). O acompanhamento terapêutico na psicose:possibilidades de uma orientação analítica. Dissertação de mestrado, Universidade Federal de Minas Gerais, Faculdade de Filosofia e Ciências Humanas, Belo Horizonte.

Pitiá, A. \& Santos, M. A. (2005). Acompanhamento terapêutico: a construção de uma estratégia clínica. São Paulo: Vetor. 
Porto, M. \& Sereno, D. (1991). Sobre acompanhamento terapêutico: a influência das ruas da cidade. In: A. Morettin et al. (org.). A rua como espaço clínico. (p. 26-27). São Paulo: Escuta.

Reis Neto, R. O. (1995). Acompanhamento terapêutico: emergência e trajetória histórica de uma prática em Saúde Mental no Rio de Janeiro. Dissertação de mestrado, Curso de Pós-graduação em Psicologia Clínica, Pontifícia Universidade Católica do Rio de Janeiro, Rio de Janeiro.

Santos, L. G.; Nogueira, A. B.; Dutra, J. B. R. O acompanhamento terapêutico como dispositivo clínico na reinserção social do psicótico. Revista de Psicologia Plural, 11 (16), 99-120. 